\title{
THE IMPLICATIONS OF RESEARCH FUNDS FOR ACADEMIC FREEDOM
}

\author{
Charles V. KidD*
}

The area of discussion initially proposed for this article was "the implications for academic freedom of research sponsored by the federal government and by large foundations." While this provided ample scope, I decided to broaden the topic to include the effects on academic freedom of all outside funds for research. This decision was made primarily because the essential relationship of research support to academic freedom arises from the terms and conditions under which funds are provided and not from the source of funds. To be explicit, the earmarking of university funds or state appropriations for research to be conducted under tightly drawn terms and conditions can pose the same threats to academic freedom as can research funds provided by the federal government or by the large foundations. More money is available for research from the government, so it is the center of attention.

\section{Research Support Has Enhanced Freedom}

The most significant effect of the rapid increase in the availability of outside funds for research over recent years has been to make meaningful the freedom of the individual faculty members and of universities. The money has invigorated science, made possible the exploration of ideas that would otherwise have remained unexplored, and opened whole fields of inquiry that would have lain fallow in the absence of funds. The money has helped universities to serve as more productive sites for research and teaching. This positive influence on intellectual freedom, which has far outweighed restrictions on freedom, is often overlooked. Problems and a degree of conflict exist, but they exist in an environment of vigorous research and education.'

- A.B. 1935, A.M. I937, Princeton University; Dr.P.A. I954, Harvard University. Associate Director, National Institutes of Health. Author, American Universities and Federal Research (ig6o); various papers on research policy and administration. Consultant to universities and foundations.

' Space does not permit a defense of these generalizations. They represent the consensus of all of the major studies of this question. One of the latest is Harold OrLeans, The Effects of Federal Programs on Higher Education (1962). He says in his introduction: "[I]t may be well to state firmly at the outset that in the judgment of the overwhelming majority of faculty and other institutional representatives, which we share, the overall effect of federal programs at universities and colleges has been highly beneficial." Another careful review of the matter has produced the judgment that "when there has been sufficient institutional self-discipline, the ways in which this federal investment have been handled to date have worked, on the whole, to uphold rather than to undermine the freedom and independent strength of American colleges and universities." Goheen, Federal Financing and Princeton University, Princeton Alumni Weekly, April r9, I963, p. 8. See also Bundy, Of Winds and Windmills: Free Universities and Public Policy (an address delivered at the Annual Meeting of the American Council on Education, Chicago, Ill., Oct. 4, $x 962$, mimeo.): "The processes of this federal investment in higher learning have on the whole been such as to enhance the freedom and independent strength of American colleges and universities." Id. at $\mathrm{r}$. 
These effects on both the individual and the university need to be stated unambiguously before more detailed considerations are brought forward, because they are the central fact and because they point to a productive general approach to the question of outside research support and academic freedom. This approach, which I shall follow, is to look for the conditions that were required for this generally favorable outcome, and for guides to insure that the outcome will continue to be favorable.

\section{II}

\section{LOOKING BackWard and LoOKIng Forward}

In assessing the effects of limitations on the freedom of individuals accompanying the acceptance of earmarked research funds, it is important to keep constantly in mind which of two viewpoints is held.

From the first viewpoint one may measure the effects of the funds, looking ahead to the elimination of defects in the system. The restrictive effects of a "project" system of support, for example, can generate difficulties which would not exist under an ideal system. As measured against an ideal, support of narrowly defined projects imposes controls on the investigator, and tends to restrict freedom to explore ideas. Similarly, the imbalance between support for research in the physical and biological sciences and support for research in all other fields is a defect if the point of reference is an ideal system.

But there is another viewpoint. That is, one may look backwards and assess the situation as it is today against what the situation would have been in the absence of federal research funds. From this vantage point, the deficiencies as seen from the first point of view become peripheral and unimportant. The general and widely held judgment is that scientists would be less able to do what they wish under circumstances congenial to them if large amounts of money were not available for research.

Some confusion over the effects of research funds is generated either because the same person may take two points of view simultaneously and unknowingly, or because debating parties talk from the two different points of view without making their points of view explicit.

Specifically on the question of the freedom of the investigator, it is possible to argue simultaneously that the increased availability of research funds extends and restricts his freedom. He can be, and generally is, freer than he would be if the funds were not available, and at the same time hampered by restrictions that would not exist under an ideal system.

An erroneous and dangerous conclusion is arrived at when one observes, looking to the future towards an ideal situation, that the situation is short of ideal, and draws the conclusion, looking from the past to the present, that the deficiencies of the system are such that it has produced bad results. It is not the same thing to say, "Earmarked funds for research impose restrictions which leave the scientist with 
less than complete freedom," and to say, "Earmarked funds for research have reduced the freedom of scientists."

\section{III}

\section{The University and the Faculty Member}

Without undertaking to define academic freedom, which others more qualified do elsewhere in this symposium, I will assume that both the freedom of the institution and the freedom of the individual are encompassed. The distinction is important in discussing effects of research funds because they have often affected the freedom of faculty members and of the university in different ways.

Outside agencies which supply research funds cannot remain aloof from the inherent strains that arise when individuals must surrender part of their immediate freedom of action to secure the greater long-range freedom which comes from membership in a group-the department, the school, or the university. Individuals sometimes do not accept the terms of the social contract that is necessary when people work within an organization. On the other hand, organizations sometimes forget that the purpose of organization is to make the work of individuals most effective.

It is not unheard of for individual faculty members to chafe under the institutional rules of the game and to maintain that local politics affecting the distribution of university research funds is more annoying than the conditions accompanying receipt of federal funds. Deans sometimes deplore the inconsiderateness of some faculty members, and presidents often seem to be concerned over the failure of some schools to bear adequately in mind their obligations as part of a university. A certain amount of tension is built into the system, and the task of all concerned is to make the tension productive. In this circumstance, grants of money from the outsidegovernmental or nongovernmental-to the individual tend to strengthen the hand of the person who controls the expenditure of the funds-the individual scientists, a research group, a department head, a dean, or the president's office. Thus the outside agencies affect the distribution of power within universities, whether they wish to do so or not, simply by the fact that they give the money to someone. Observe what grants to individual scientists-a widely applauded means of distributing research money-may do. They can make the individual largely independent of the university, and tend to shift his loyalties outside the university. In one sense, this expands the freedom of the individual. But it can also be a divisive force that weakens the university and decreases its capacity to act effectively as the institutional device for protecting the freedom of all faculty members. If the individual is inclined to flaunt the rules and mores of the institution, the outside money strengthens his hand. Much government and university money has been given, in effect, directly to individuals, and some of them have tended to become independent research entrepreneurs. The grants in this circumstance markedly expand the freedom 
of individuals over the short run, but they tend to restrict the freedom of the department, the school, and the university.

When outside research funds are made available under conditions that give department heads, deans, or presidents control over expenditures, their relative power increases. If this power is not exercised judiciously, and sometimes if it is used wisely, one hears charges of administrative domination and interference with the freedom of the scientist. Accordingly, the relationships between outside support of research and academic freedom are far from simple. They go to matters more fundamental than such things as imposition of controls on publication of data or the clearance of scientists to work on secret projects. In contrast with some gross threats to academic freedom that unite the institution and the faculty in determined defense of a shared ideal, outside research funds often tend to emphasize the differences in the way faculty members and the institution define freedom.

A university which has avoided, or overcome, the potentially divisive effects of outside research funds has established the most significant prerequisite to maintenance of freedom. The attainment of a consensus, widely shared among the faculty and administrative officers of a university, as to the central purposes of the university, the boundaries of its functions, and the standards of excellence expected of faculty and students, is the prime condition for receipt of outside research funds upon terms set by the university. And by setting the terms of acceptance, the university remains free.

\section{IV}

\section{The Limits of Scientific Freedom}

The nature of freedom in science and in society is a philosophical problem that I am not equipped to handle in a professional manner. ${ }^{2}$ However, some elements of the problem relating to the scientist and to the university which seem significant to me are outlined below.

First, no scientist is absolutely free in every sense. For example, there are times when his judgment would call for an increase in the rate of his work and for an increase in the investment for his work. Often his judgment has to be overridden because there is not money enough, space enough, nor people enough to go around. The fact that the scientist's judgment is overridden does not necessarily constitute an improper limitation on his freedom. What the scientist legitimately asks is that the decisions on allocation of resources be made intelligently, which means with appropriate participation of scientists, and that the decisions be made and changed in a way that is not disruptive. In an important sense, the question whether restrictions on the resources available to scientists constitute an improper restriction of their area of freedom depends not upon the degree of restriction but upon the propriety of the process by which the decision to restrict was reached.

The problem is dealt with formally in an interesting book, F. E. Oppenhem, Dimensions of FREEDOM (I96I). 
Second, those who provide earmarked funds for research have a right to impose conditions upon the use of funds, and to stipulate the terms and conditions under which they may be used. The fact that they may limit the freedom of the scientist does not necessarily mean that they improperly limit his freedom. The problem, of course, is to define improper limitations and to establish the conditions that avoid the imposition of improper limitations.

Third, a scientist who is a faculty member has certain obligations to the university which involve a short-range, voluntarily accepted set of limitations upon his freedom of action as one of the prices to be paid for the establishment and maintenance of a strong university over the long run. A scientist who ignores the rules of the game is not sustaining freedom against tyranny, or protecting science against administrators, but simply failing to exercise the responsibility without which freedom is meaningless. These observations are pertinent to faculty members who invoke academic, scientific, or any other kind of freedom to do whatever they want to do.

Fourth, freedom cannot be adequately discussed solely in terms of rules or the absence of rules. The process by which rules are formulated and enforced is not a mechanical matter, but important to the concept of freedom itself. As in our form of government, the means are as important as the ends.

Finally, universities are likewise not free in any absolute sense. They serve society. They serve uniquely by sustaining independence from the immediate forces imposed by society. But they also serve by responding to a degree to the immediate demands of society. Wriston has stated the problem well:" "If the college were wholly alien to its environment it could not perform its function. ... On the other hand, if it yields completely to its environment, it equally fails in its objectives. It must maintain a realistic contact without compromising its essential function."

This generalization is relevant to the acceptance of federal research funds by universities. In a superficial sense, it is true that universities need not accept federal research funds. It is sometimes said that universities can and should avoid any threats to academic freedom arising out of the acceptance of outside research funds by refusing to take the money. However, it would be frivolous to dismiss the problem of academic freedom and outside research support by taking this shallow view. No university can hope to become or remain first class in the total array of physical and biological sciences unless it relies heavily upon federal research funds. Moreover, the universities comprise a unique resource without which research essential to the attainment of vital national goals cannot be done. Since universities have obligations to the nation, the nature, extent, and conditions of participation pose complex problems for them. Complete aloofness is often not the proper solution. So the problems cannot be dodged. Universities must become involved with federal research and sustain their freedom in the face of the involvement. How they are to do this is the root of the problem of academic freedom and outside research funds.

'H. M. Wriston, The Nature of the Liberal Arts College 20 (I937). 
If one accepts the premise that academic freedom is not an absolute and unlimited right, then some limitations are justified because other values and goals which conflict, at least specifically, with academic freedom are properly given some weight. National defense, for example, is one of these goals which may conflict. Those concerned with academic freedom often express concern over the threats to academic freedom arising from secrecy measures imposed to enhance the nation's military defense. There is no reason why academic freedom should be pushed to any extreme when so doing would divulge militarily useful secrets to a potential enemy. If so, it could be said that academic freedom posed a threat to national security. This hypothetical extreme is stated simply to establish the fact that academic freedom is not an absolute right. The case for a rather aggressive position in relation to threats to academic freedom seems to me to be justified not because the freedom is an inherent unlimited right, but because the case rests on more subtle, generally less appealing, and more widely misunderstood grounds than is the case with such goals as protection of the national defense. Accordingly, academic freedom must generally be defended with exceptional vigor if the outcome is to be in fact a reasonable compromise between academic freedom and other goals and values.

\section{V}

\section{University Rules, Obligattons, ANd Rights}

Most rules of conduct, or rules regulating the expenditure of money, restrict the freedom of individuals over the short run. But they do not necessarily improperly restrict their freedom. Thus, when a university places limits upon the nature of consultant activity, upon the time that can be spent consulting, and upon the income that can be derived from consulting, faculty members have had their freedom curtailed. On what grounds are these restrictions justified? On the ground that the university serves certain ends, that the faculty member has an obligation to serve those ends, and on the ground that the ends are subverted by too much consulting of the wrong kind. The restriction on freedom becomes improper only if the restriction is greater than is required to insure that the objectives of the university are not subverted.

The phrase "over the short run" is reiterated, because rules that inhibit individuals over the short run will, if properly framed and administered, contribute to protection and expansion of the freedom of the individual and the group-the faculty-over the long run. Universities are supported from private and public sources because they perform functions useful and even necessary to the welfare of the society of which they are a part. This usefulness is not utilitarian in a narrow sense. It encompasses, for example, the functions of providing the environment where the degree of intellectual freedom afforded the individual is greater than in any other institution. Rules carefully designed to insure that this freedom is protected-including such rules as those forbidding excessive or improper consulting 
activities-are a necessary means to the maintenance of the freedom of individuals and the institution over the long run.

Universities have a clear obligation to see that the rules established by federal agencies for the expenditure of research funds are observed. Indeed, the scrupulous fulfillment of this obligation is a critically important prerequisite to the maintenance of the freedom of universities. It may seem paradoxical to assert that the imposition upon faculty members of rules and requirements relating to the use of money is a contribution to the freedom of science. But this is in fact true because if universities do not establish the conditions insuring that federal funds are handled prudently, they will be over the long run subjected to outside controls.

Universities face at least two broad problems in dealing with the problem of rules. The first is to establish the internal conditions that permit the establishment and observance of rules. Such matters as consideration of what the rules should be, care in consulting appropriate people in an appropriate way on appropriate matters, and establishment of the conditions under which observance of the rules emerges as a consequence of a consensus are of the utmost importance. Such activities can be called administration, and when administration is viewed in this light it is a task of the greatest difficulty and significance. Perhaps the most accurate measure of the significance of administration defined in these terms is the reaction that is provoked by poor administration. A second problem is the exercise of an adequate degree of control over the conditions imposed by federal agencies. While universities have a clear obligation to observe the federal rules that exist, they have an equal right and obligation to protest existing or proposed terms and conditions which they find objectionable. Their effectiveness in controlling the terms and conditions under which they will accept federal research funds is the measure of their independence and freedom.

On the whole, the universities have been vigilant and effective in detecting and dealing with what they consider improper rules. The refusal of many institutions to accede to the imposition of the inquiry into beliefs required by the affidavit under the National Defense Education Act loan requirements played a large part in securing a satisfactory amendment to the Act. More recently, Harvard University and Massachusetts Institute of Technology refused to accept the terms of an Atomic Energy Commission contract which set unacceptable limitations on employment and visits of aliens and Soviet bloc nationals and on exchange of data between those employed at the AEC-supported installations and Soviet bloc scientists. ${ }^{4}$ The universities bargained with AEC, and arrived at a satisfactory compromise. A somewhat similar situation has arisen among the National Institutes of Health, institutions receiving research grants, and the scientific community. The NIH adopted a new manual of rules after a congressional committee pointed out some practices which could not be defended. Many universities and scientists feel that the rules go

\footnotetext{
Atomic Energy Commission, Energetic Bargaining Brings Agreement on University Contract Clauses on Security Information, Science, April 5, 1963, p. 38 .
} 
further than is reasonable. In this case, the bargaining involves universities through such agencies as the American Council on Education, specialized schools through such groups as the Association of American Medical Colleges, and the scientific community. In all the recent instances when universities, the federal government, and the scientific community have had difficulty in arriving at an acceptable set of rules, the element of negotiation and compromise has been important. While there are certain basic fundamentals beyond which none of the parties can retreat, there does exist in practice an area of negotiation within which a satisfactory compromise can be worked out without the sacrifice of fundamentally important values. If this state of affairs is to continue, the sine qua non is the ability of the universities to exert countervailing pressure when they are pressed towards unacceptable terms and conditions.

VI

\section{The Federal Side}

The federal government has a clear right, and even an obligation, to spend a substantial proportion of its research budget for the acquisition of knowledge relating to the operating missions of the various federal agencies. When a federal agency needs certain data, and provides funds to a university to produce the data, it is no infringement upon the freedom of the scientist over the short run to insist that he work on the problem agreed upon if he wants to have his work financed by the government. The investigator has a right to do whatever he wants; but he does not have a right to do whatever he wants and to expect that support will necessarily continue if he has accepted money from any source with the understanding that he will pursue a specified task. For the long run, as pointed out below, there has to be adequate federal support for research with broadly specified or unspecified goals.

One way to reduce differences between federal agencies and universities, and hence to reduce pressures on them to act in response to outside forces, is to extend the statutory missions of federal agencies so that they are able to support the full range of university activities on terms congenial to universities. A move in this direction would rest upon the assumption that the welfare of the nation depends heavily upon strong independent universities, and that broad assistance from the federal government is needed to insure that the nation will have such a set of universities.

In actual practice, the various federal agencies have modified to some extent the terms and conditions under which they provide research funds to universities so as to take into account the long range reliance of the government upon strong universities. As examples of this adaptation, one sees such developments as the institutional research grant of the National Science Foundation under which funds are made available to universities for the support of science as the universities see fit. Another example is the support of salaries of a large number of faculty members for the duration of their careers by the National Institutes of Health. Finally, the increasing 
national attention to the construction of physical facilities and to the support of graduate students is evidence of the evolution of federal support towards a system more nearly congruent with the needs of universities. It is a system under which both individual scientists and universities have a greater degree of freedom. However, this is a piecemeal, partial adaptation guided by no consistent view, and governed by no coherent statutory base.

As long as the federal agencies cannot support all university functions, strain will exist because some universities will tend to stretch the use of federal funds to finance functions not clearly supportable. The agencies and Congress will tend to resist the extension of special purpose federal programs to meet the general needs of universities. The issue of freedom of the universities and the freedom of scientific inquiry is certain to persist in this environment.

\section{VII}

\section{The Individual Scientist and the Scientific Community}

In stressing the significance of the strength of the university as a bulwark of academic freedom, the role of the individual, and of organized scientists, must also be recognized. Ways in which the freedom of the individual may be affected by research funds have been discussed above, but some additional facets of the topic deserve discussion.

From the viewpoint of the individual, the sheer size of the research enterprise generates problems. Indeed, the problems associated with size-such as the inescapable needs for organization, for a hierarchy of decisions, and for devotion of time to administration-are perhaps the central issues in considering the effects of outside research funds upon the freedom of individuals. The most important aspect of federal funds may well be not the fact that they are government funds, but the fact that they make possible a very large national system of research. A discussion of the means by which individual creativity is to be sustained in a system which must be organized and in a sense directed is beyond the scope of this paper, but it is close to the center of the question of the freedom of the individual in a large research system.

Various forms of organized activity by scientists have much to do with the effect of research funds on the freedom of the individual. Obviously the effectiveness of faculty participation in the determination of university policy, including but not limited to research matters, has a direct bearing upon the freedom of individuals. Similarly, the vigor with which professional societies, including both the specialized groups and more general scientific bodies such as the National Academy of Sciences, defend the freedom of the individual and urge the acceptance of responsibilities by the individual has a great deal to do with the maintenance of scientific freedom in the presence of large-scale governmental research. It is worth remembering that the back of McCarthyism as it affected federal research grants to investigators in universities was broken by a report of a committee of the National Academy of Sciences, 
under the chairmanship of J. A. Stratton of Massachusetts Institute of Technology. These principles were enunciated: ${ }^{5}$

I. The test in the award of grants and contracts for unclassified research should be the scientific integrity and competence of the individuals responsible for carrying out the research, and the scientific merits of their program.

2. When an official of the government comes into possession of evidence which in his opinion indicates the possible existence of disloyalty in violation of law, he should promptly refer that information to the federal agencies of law enforcement established to deal with such matters.

3. An allegation of disloyalty should not by itself be grounds for adverse administrative action on a grant or contract for unclassified research by scientifically competent investigators; if the indications of disloyalty appear sufficiently serious to warrant any action at all, the government in the opinion of the Committee has no other course than to bring formal charges and to produce the evidence in open hearing before legally constituted authority.

More recently, the scientific community was somewhat disturbed by rules established for the research grant program administered by the National Institutes of Health. In April I963, the American Society of Biological Chemists passed the following resolution, which expressed every important facet of the problem except the obligations of universities: ${ }^{6}$

The condition of mutual dependence between the federal government and institutions of higher learning and research is one of the most profound and significant developments of our time. It is abundantly clear that the fate of this nation is now inextricably interwoven with the vigor and vitality of these institutions. In turn, the fate of these institutions is dependent upon the wisdom and enlightenment with which federal funds are made available in support of these activities.

It is imperative, therefore, that the conditions governing this mutual interdependence be subject to continuing appraisal and that the policy underlying administration of federal programs in support of research assures that this relationship will continue to be mutually beneficial.

The basic instrument which has served to define these relationships has been the research grant, a device which should place the federal government and the grantee institution in a relationship of trust while conveying to the individual investigator public funds to be prudently expended in the accomplishment of his research objectives.

The necessity for clearer definition of the relationships involved has been brought into focus by the criticisms recently directed by the Intergovernmental Relations Subcommittee of the House Committee on Government Operations against the management of the research grants program of the United States Public Health Service.

While regretting the manner of criticism of the House Committee and their failure to provide constructive leadership, we suggest that the time is indeed opportune and the moment critical for appraisal of the relationships which properly should obtain among the federal government, universities, and scientific investigators if the national interest is to be served.

Accordingly, we, the members of the American Society of Biological Chemists, do

"Press Release of April 4, 1956 from the White House on a report of the Committee on Loyalty in Relation to Government Support of Unclassified Research of the National Academy of Sciences.

'A resolution adopted by the American Society of Biological Chemists, at the Annual Meeting of the Association, Atlantic City, N.J., April 18, 1963. 
urgently request that the National Academy of Sciences undertake a critical appraisal of these relationships in the support of fundamental research, not only by the NIH but by all other federal agencies which are substantially so committed.

It is our earnest hope that, following such appraisal, the Academy will enunciate the principles and philosophy which will serve as basic policy in the future conduct and administration of federal programs in support of fundamental research.

The Academy has indicated that it will undertake the task urged upon it by the Society.

Another form of scientific organization deserving special attention is the system of scientific groups established by both governmental and private organizations to advise them on the distribution of research funds. These advisory bodies, which have functions ranging from broad policy matters to highly technical decisions, are in my judgment an administrative invention of great significance. The scientific advisory groups provide a means through which scientists can participate in the decisions vitally affecting the scientific community. The groups are, in addition, a powerful device for improving scientific communication. The influence of these groups raises a number of problems, such as the possibility of conflict of interest, bias in decisions, and the propriety of giving the effective power of decision to individuals who cannot be held responsible. In particular, the subtle coercive effects of group judgments on the work of peers must be considered. On balance, however, the extensive participation of scientists in the decision making process tends to expose the system to scrutiny and hence to establish conditions favorable to protection of the freedom of individuals. This participation is also a useful means of exposing to the scientific community the needs of grantors which result in restrictions on the use of funds.

These various forms of organization and their activities are cited to emphasize the indispensable role that purposeful organized activity from within the scientific community plays in securing a proper balance between scientific freedom and the obligations of the scientist. This activity is in a general sense political. The scientific community cannot protect the freedom of science and of the scientist by being apart from and above political action. Funds for research provided by government, and in a sense by private sources, come from sources outside the scientific community and many important decisions affecting the use of funds are made outside the scientific community. Only by acting politically can the academic community exercise a proper degree of control over these decisions.

\section{VIII}

\section{ConcLusion}

On balance, outside research funds, including federal funds, have extended the freedom of both individual investigators and universities. This is a net judgment, and the relationships between universities and granting agencies have not been 
without strain. Certain general characteristics of outside funds and some specific actions have tended to restrict freedom.

There has been an area of inherent strain between government and universities as a consequence of government financing of research in universities. The totality of federal research support, as well as federal support for some fields of education, does not extend to support of the total functions of universities. This leads to a feeling on the part of many scientists that the federal aid restricts their freedom. It also generates pressures which tend to distort the function of universities and to reduce their control over some major internal matters. Government consists of the legislative, as well as the executive branch. Some fundamental American beliefs reflected in law and in the opinions of legislators are not entirely congenial to universities. The value placed outside the academic community upon academic freedom and on the independence of universities is not as high as the value placed upon such matters as scrupulous accounting for the expenditure of tax funds and production of practical results from research. Such differences in the intensity of commitments to conflicting sets of values are the basic source of tension and disagreement over the degree of priority to be given to academic freedom over other competing ends.

The existence of tensions between government and universities constitutes neither a condemnation of either party nor a demonstration that the system is basically faulty. The tensions can be productive provided the bargaining strength of the parties is reasonably matched, and provided the parties have reasonable and welldefined goals which guide their bargaining. The attainment and maintenance of reasonable parity in bargaining strength is a shared responsibility. Government has an obligation to strengthen the position of universities because they tend to be the weaker parties.

The major contribution from the side of government would be further evolution of means for taking into account in a more satisfactory manner the educational, as well as the research, needs of the nation and hence the full needs of universities. This would involve such things as payment of the full indirect, as well as the direct, cost of research, provision of additional fellowships which fully cover the cost of education, provision of large sums for construction of academic facilities with modest matching requirements, and provision of substantial research funds under conditions. leaving broad discretionary authority to universities. From the side of the universities, continuing progress towards establishment of clear institutional goals is important. And of equal importance is their ability to muster the intellectual, administrative, and financial strength necessary if they are to exercise countervailing. pressure against forces tending to divert them from their defined goals. 